\title{
Prensa en el Smartphone
}

\section{Modelos aplicados en los diarios españoles y necesidades de desarrollo}

\section{Newspapers on the Smartphone Models applied in the Spanish press and needs of development}

\section{Carmen Costa Sánchez}

Profesora Ayudante Doctora e investigadora del Grupo de Investigación Cultura e Comunicación Interactiva (Departamento de Humanidades, Área de Comunicación Audiovisual y Publicidad, Universidade da Coruña)

Fecha de recepción: 17 de abril de 2013

Fecha de revisión: 22 de mayo de 2013

Para citar este artículo: Costa Sánchez, C. (2013): Prensa en el Smartphone. Modelos aplicados en los diarios españoles y necesidades de desarrollo, Icono 14, volumen 11 (2), pp. 07-30. doi: 10.7195/ri14.v11i2.591 


\section{Resumen}

Mientras la prensa en papel continúa perdiendo lectores e inversión publicitaria, la prensa online ensaya fórmulas para rentabilizar el negocio en la Red, que van desde modelos gratuitos a modelos paywall o de pago total. El desembarco de nuevos dispositivos móviles (fundamentalmente, tablets y smartphones) suma una nueva vía para canalizar los contenidos y una nueva plataforma también para rentabilizarlos. Pero, ¿cómo debe ser el modelo de prensa para smartphone? ¿Cómo organizar y presentar los contenidos optimizando un medio que se emplea en momentos intersticiales y que presenta unas características técnicas propias? Y más aún, ¿cómo rentabilizarlos? El presente artículo estudia las aplicaciones para Android e iOS de la prensa española más leída, con objeto de retratar las características de los modelos imperantes, pero también con intención de señalar las mejoras necesarias para la optimización del medio móvil.

\section{Palabras clave}

Smartphone - Prensa móvil - Dispositivos móviles - Android - iOS - Aplicaciones Periodismo

\section{Abstract}

While the print-press continues losing readers and advertising investment, the on-line press tests manners for making profitable the online business, which can go from free to paywall models. At the arrival of new mobile devices (primarily, tablets and smartphones) there is a new road to pipe the contents and a new platform also for making them profitable. But, how has to be the smartphone news app model? How have the editors to organise and present the contents for a platform that is employed at interstitial moments and that presents some own technical characteristics? And still more, how can they make them profitable? The present research article studies the Spanish most read newspapers applications for Android and iOS to portray the characteristics of the main models, but also with the intention to highlight the necessary improvements for their optimal use.

ICONO14 | Año 2013 Volumen 11 № 2 | ISSN: 1697-8293 | DOI: ril4.v1 1i2.591 


\section{Key Words}

Smartphone - Newspapers applications - Mobile devices - Android - iOs -Applications - Journalism

\section{Periodismo en la pequeña pantalla. Anteceden- tes y evolución: de los SMS a las apps}

Todo cambio tecnológico en los medios de comunicación implica una adaptación en las estructuras, los usos, los lenguajes y las posibilidades que de ello derivan. También la adopción social de dicha tecnología influye en los cambios. Así, al igual que el ciberperiodismo pasó por distintas etapas desde su arranque a mediados de los años 90 hasta hoy, también el periodismo móvil ha pasado por diferentes estadios hasta su configuración actual y es más que probable que los cambios no hayan hecho más que empezar. La evolución de las características técnicas de los dispositivos ha incidido en dicho proceso.

Recurriendo a Aguado y Martínez (2008), Canavilhas (2009) y Lerma y Cobos (2013) podemos diferenciar tres etapas en la evolución del smartphone como herramienta informativa para los ciudadanos:

En una primera etapa, de adaptación, que difícilmente podríamos calificar de periodismo, nos encontramos con contenidos informativos para móviles poco interactivos, de alerta de titulares muy vinculados a la última hora, que se enviaban en formato SMS o MMS y que suponían un pequeño pago para el suscriptor al que se le ofrecía un nuevo servicio vinculado a la marca. Los formatos se veían condicionados por las bajas velocidades de acceso, la pequeña dimensión de la pantalla de los móviles, las interfaces poco intuitivas, así como el precio de los servicios (Canavilhas, 2009).

En un segundo momento, cuando comienza la incorporación de Internet a los teléfonos móviles, los contenidos informativos empiezan "a dejar de ser una adaptación automática y a responder a una estructura específica y a una concepción cada vez más estratégica de la plataforma móvil" (Aguado y Martínez, 2008:112). Mediante el protocolo WAP, se permitía una lenta y dificultosa navegación por una versión web del diario con textos cortos e imágenes en baja calidad. 
En 2005, se aprueba el dominio .mobi para el registro de sitios web diseñados para dispositivos móviles. Se reconocen porque en su dirección url se utiliza la extensión http://m. Facilita la lectura y navegación respecto de la página web del diario, aunque el usuario debe asumir el coste derivado de tener en su teléfono activada una tarifa de datos.

Casi la totalidad de los grupos mediáticos españoles y de sus principales cabeceras incorporaron entre 2000 y 2002 este tipo de servicios y a partir de 2002, de imágenes y portales WAP como una extensión de los servicios de alerta por correo electrónico o boletines online (Aguado y Martínez, 2008).

La tercera etapa se corresponde con la era de las aplicaciones, en la que nos encontramos. Con la generalización de los accesos 3G y el lanzamiento de los smartphones, se llega a una tercera fase con el desarrollo de aplicaciones propias para acceder a contenidos informativos georeferenciados de naturaleza multimedia y la posibilidad de participar, comentando o enviando contenidos.

Es por ello que en los equipos y plantillas de las empresas periodísticas comienza a haber profesionales dedicados exclusivamente al mantenimiento del medio móvil. “Todos los grupos con los que nos entrevistamos tienen ya un departamento, dentro del organigrama general, dedicado al mantenimiento de los contenidos móviles e integrados por una plantilla (de entre una y dos personas) dedicada, exclusivamente, al dispositivo móvil" (Sánchez Valverde et al., 2010: 3).

Tal y como explica García Hervás (2010), con una base mundial de más de 4.600 millones de clientes a principios de 2010 y una tasa de penetración del 113,9 por ciento en España, superando los 54,4 millones de líneas, las comunicaciones móviles permiten potenciar la utilidad de las redes que se interconectan a ella, principalmente Internet, consiguiendo una sinergia que combina movilidad con el catálogo de servicios multimedia interactivos existente en la Red.

Los teléfonos móviles y en concreto los smartphones cuentan con tasas de penetración muy altas en la región europea, lo que implica un mercado muy apetecible para cualquier empresa de creación de contenidos digitales. Tal y como se recoge en el Informe Medición de la Sociedad de la Información 2010 (UIT), el sector de la banda ancha móvil está evolucionando de manera prometedora, de manera que la introducción del acceso a Internet móvil de alta velocidad en cada vez más países aumentará rápidamente el número de usuarios de Internet, sobre todo, en los países en desarrollo. En cifras, el número de abonados a la banda ancha móvil ha 
ido creciendo paulatinamente y en 2008 superó a los de banda ancha fija a nivel mundial.

Según la encuesta Navegantes en la Red de AIMC (2013) realizada a usuarios de Internet en España, el porcentaje de usuarios que acceden a Internet desde sus teléfonos móviles (79\%) ya supera a aquellos que acceden desde su ordenador fijo $(78,8 \%)$ y se aproxima muy de cerca a los usuarios de portátil (80,9\%).

Respecto al uso que se hace de Internet en movilidad, la lectura de prensa online en el smartphone alcanza el 41,3\%, ubicándose en segundo lugar, por detrás del ordenador (sobremesa o portátil) y superando la lectura en tableta, que se mantiene en unos niveles del 23,6\% (en datos de AIMC, 2013). En la comparativa con otros medios de comunicación, en concreto el acceso a prensa, radio o televisión, es la lectura de prensa la actividad predominante.

Otros estudios han avalado el potencial periodístico del medio móvil. En datos del realizado por el Pew Research Center, How mobile devices are changing community information environments, se recoge que el $47 \%$ de los americanos adultos usan sus teléfonos y tabletas para obtener noticias locales e información. En datos del IV Estudio Anual IAB Spain Mobile Marketing (de Iab Spain Research y TheCocktail Analysis ${ }^{1}$ ), leer la prensa es la cuarta actividad realizada a diario en la Internet móvil después de chatear, usar el correo electrónico y acceder a redes sociales $\mathrm{y}$ de un total de 13 posibilidades.

“El ritmo al que crecen los usuarios de estos servicios, el abanico de posibilidades que se están abriendo desde el punto de vista tecnológico, y el significativo nivel de ingresos que están generando, de forma generalizada, los contenidos móviles han hecho sospechar que, lo que hoy es sólo una salida más, puede llegar a convertirse, en un tiempo relativamente breve, en uno de sus motores más importantes, junto con las ediciones web" (Sánchez Valverde et al., 2010: 15).

La adaptación de las empresas de comunicación a los nuevos soportes y formatos en movilidad no se ha hecho esperar. Medios tradicionales (de todos los sectores, prensa, radio y televisión), así como medios nativos digitales intentan dotar de contenidos a las nuevas pantallas.

Desde el punto de vista empresarial, la oferta de una aplicación para móviles, además de un nuevo servicio a los usuarios, puede suponer una interesante vía de consolidación de la marca y un nuevo canal para obtener ingresos publicitarios o por contenidos.

DOI: ri14.v11i2.591 | ISSN: 1697-8293 | Año 2013 Volumen 11 N² 2 | ICONO14 
La fidelidad que aporta la app en comparación con la web supone un valor añadido: si el usuario dispone de la aplicación, tendrá un recuerdo permanente del medio en pantalla. “The smartphone's application icon can act as a reminder to use the app, Nielsen says. This icon should be taken seriously and sufficient effort spent during the app's design process to make it attractive and appealing", explica Lauren Seaton en el studio In-depth news for smartphones (Digital News Test Kitchen, 2010).

Las empresas periodísticas se encuentran, por lo tanto, con un dispositivo de uso generalizado en España, donde la consulta de información de actualidad es una actividad que se añade a las específicas de canal de comunicación interpersonal. Además, su portabilidad, así como su potencial acceso a la Red, lo han convertido en un dispositivo que acompaña al usuario a todas partes (everywhere) ofreciéndole la posibilidad de estar siempre conectado (always on).

Las preguntas que se abren ante el panorama hasta aquí descrito son:

En primer lugar, ¿está apostando la prensa diaria española por el mercado de aplicaciones o confía en la web del diario como elemento convergente para cualquier dispositivo de acceso a Internet? En un segundo término, ¿qué ofrecen las aplicaciones generadas a los usuarios en su intento de adaptación al medio móvil? Y finalmente, ¿cómo están intentando las empresas periodísticas rentabilizar estos contenidos?

El presente trabajo pretende encontrar algunas respuestas y determinar las necesidades a las que la industria de la prensa española, en su concepción del modelo de periodismo en el smartphone, deberá responder en los próximos años.

\section{Material y Método}

Para la realización del presente estudio se han analizado las aplicaciones creadas para los sistemas iOS y Android por parte de las cabeceras que conforman el ranking de los 20 diarios más leídos en España (AEDE, 2012). Cabe destacar que dicho conjunto de diarios se mantiene como el más leído en España a lo largo de 2011, 2012 y lo que llevamos de 2013 (EGM), por lo que la muestra de estudio está plenamente actualizada, con la única excepción del diario Público, que sufre un proceso de reconversión al medio digital debido a la crisis económica.

No obstante, se ha decidido mantener el ranking manejado por la fuente de

ICONO14 | Año 2013 Volumen 11 N² | ISSN: 1697-8293 | DOI: ri14.v11i2.591 
referencia (es decir, la Asociación de Editores de Diarios Españoles) en su versión más actualizada (2012), por los siguientes motivos:

- Tratarse del informe sobre el sector de la prensa diaria más relevante a nivel España.

- No suponer modificaciones en el aspecto metodológico y de resultados manejado en el presente trabajo ya que el diario que sustituye a Publico en el ranking de lectores en el último año, el balear Última hora, carece de un modelo propio y diferenciado de aplicación para smartphone en ambos sistemas.

- El diario Publico consiguió convertirse, a pesar de su juventud (se crea en 2007), en un medio de comunicación muy leído en España, en competencia con cabeceras generalistas de larga tradición, lo que hacía interesante conocer el modelo informativo propuesto para la nueva plataforma, así como contribuía a enriquecer los resultados del presente estudio.

La primera parte de la investigación, por lo tanto, se dedica a diagnosticar el número de aplicaciones para smartphone de la prensa diaria española más leída. En concreto, siguiendo el ranking de diarios elaborado, se analizaron las siguientes cabeceras:

\section{Diarios analizados y aplicaciones disponibles}

\begin{tabular}{|l|l|l|l|l|l|}
\hline Nombre & $\begin{array}{l}\text { Grupo } \\
\text { propietario }\end{array}$ & $\begin{array}{l}\text { Tipo de } \\
\text { información }\end{array}$ & $\begin{array}{l}\text { Número de lectores } \\
(000)(2011)\end{array}$ & \multicolumn{2}{|l|}{$\begin{array}{l}\text { Tipo de aplicación } \\
\text { disponible }\end{array}$} \\
\hline & & & & iOS & Android \\
\hline Marca & $\begin{array}{l}\text { Unidad } \\
\text { Editorial }\end{array}$ & Deportiva & 2.960 & $x$ & $x$ \\
\hline El Pais & Prisa & General & 1.915 & $x$ & $x$ \\
\hline As & Prisa & Deportiva & 1.470 & $x$ & $x$ \\
\hline $\begin{array}{l}\text { El Mundo del } \\
\text { siglo XXI }\end{array}$ & $\begin{array}{l}\text { Unidad } \\
\text { Editorial }\end{array}$ & General & 1.234 & $x$ & $x$ \\
\hline La Vanguardia & Grupo Godó & General & 849 & $x$ & $x$ \\
\hline Marca & $\begin{array}{l}\text { Unidad } \\
\text { Editorial }\end{array}$ & Deportiva & 2.960 & $x$ & $x$ \\
\hline El Pais & Prisa & General & 1.915 & $x$ & $x$ \\
\hline As & Prisa & Deportiva & 1.470 & $x$ & $x$ \\
\hline $\begin{array}{l}\text { El Mundo del } \\
\text { siglo XXI }\end{array}$ & $\begin{array}{l}\text { Unidad } \\
\text { Editorial }\end{array}$ & General & 1.234 & $x$ & $x$ \\
\hline
\end{tabular}




\begin{tabular}{|c|c|c|c|c|c|}
\hline \multirow{2}{*}{$\begin{array}{l}\text { Nombre } \\
\text { La Vanguardia }\end{array}$} & \multirow{2}{*}{$\begin{array}{l}\text { Grupo } \\
\text { propietario } \\
\text { Grupo Godó }\end{array}$} & \multirow{2}{*}{$\begin{array}{l}\text { Tipo de } \\
\text { información } \\
\text { General }\end{array}$} & \multirow{2}{*}{$\begin{array}{l}\text { Número de lectores } \\
(000)(2011) \\
849\end{array}$} & \multicolumn{2}{|c|}{$\begin{array}{l}\text { Tipo de aplicación } \\
\text { disponible }\end{array}$} \\
\hline & & & & $x$ & $x$ \\
\hline$A B C$ & Vocento & General & 660 & $x$ & $x$ \\
\hline $\begin{array}{l}\text { La Voz de } \\
\text { Galicia }\end{array}$ & $\begin{array}{l}\text { Corporación } \\
\text { Voz de Galicia }\end{array}$ & General & 623 & $x$ & $x$ \\
\hline $\begin{array}{l}\text { El Correo } \\
\text { Español }\end{array}$ & Grupo Vocento & General & 443 & $x$ & - \\
\hline $\begin{array}{l}\text { La Nueva } \\
\text { España }\end{array}$ & Prensa Ibérica & General & 356 & $x$ & - \\
\hline \multirow[t]{2}{*}{$\begin{array}{l}\text { El Heraldo de } \\
\text { Aragón }\end{array}$} & $\begin{array}{l}\text { Heraldo de } \\
\text { Aragón S.A. }\end{array}$ & General & 300 & $x$ & $x$ \\
\hline & & & & iOS & Android \\
\hline Publico & $\begin{array}{l}\text { DisplayConnec- } \\
\text { tors S. L. }\end{array}$ & General & 299 & $x$ & $x$ \\
\hline La Razón & Grupo Planeta & General & 298 & $x$ & - \\
\hline Levante & Prensa Ibérica & General & 283 & $x$ & $x$ \\
\hline Faro de Vigo & Prensa Ibérica & General & 267 & $x$ & $x$ \\
\hline La Verdad $^{2}$ & Vocento & General & 265 & $x$ & $x$ \\
\hline $\begin{array}{l}\text { El Diario } \\
\text { Vasco }\end{array}$ & Vocento & General & 246 & $x$ & $x$ \\
\hline Información & Prensa Ibérica & General & 244 & $x$ & - \\
\hline
\end{tabular}

Tabla $n^{\circ}$ 1: Diarios analizados y aplicaciones disponibles. Fuente: Elaboración propia a partir de AEDE (2012).

La muestra de estudio por lo tanto estuvo configurada por un total de 20 cabeceras de información general y deportiva y 36 aplicaciones, de las cuales finalmente fueron estudiadas 33 por problemas en el acceso, en su navegación o funcionamiento. El período de estudio de las apps de Android fue del 10 al 17 de Marzo de

\section{Número de unidades estudiadas}

\begin{tabular}{|l|l|l|l|}
\hline $\mathbf{N}^{\circ}$ cabeceras & $\begin{array}{l}\mathbf{N}^{0} \text { total de aplicaciones } \\
\text { estudiadas }\end{array}$ & $\begin{array}{l}\mathbf{N}^{0} \text { aplicaciones } \\
\text { android }\end{array}$ & $\mathbf{N}^{0}$ aplicaciones i0S \\
\hline 20 & 33 & $15^{3}$ & $18^{4}$ \\
\hline
\end{tabular}

Tabla $n^{\circ}$ 2: Número de unidades estudiadas. Fuente: Elaboración propia 
2013, mientras que las aplicaciones para el sistema iOS fueron estudiadas del 12 al 19 del mismo mes. En ambos casos, el período de estudio fue de una semana. El soporte de estudio varió, lógicamente, para ambos casos: las aplicaciones para Android fueron estudiadas en un Samsung Galaxy S3, mientras que las aplicaciones para el sistema de Apple se estudiaron en un iPhone 4S.

La segunda parte de la investigación pretende realizar un análisis de dichas aplicaciones informativas en base a una serie de ítems que buscan realizar una descripción en términos de diseño y organización de contenidos, nivel de personalización, nivel de participación y multimedialidad (es decir, empleo e integración de recursos multimedia), usabilidad (facilidad de navegación), utilidades basadas en la geolocalización y modelo de negocio.

Partiendo de análisis previos centrados en aplicaciones periodísticas o informativas en dispositivos móviles (Canavilhas, 2009; Navarro y Lisboa, 2012; Carvajal, 2013) e incorporando contenidos adecuados a los objetivos de la presente investigación, se elaboró una ficha de estudio configurada de la siguiente forma:

\section{Modelo de análisis aplicado}

\begin{tabular}{|l|l|}
\hline Elemento & Indicadores \\
\hline Diseño & $\begin{array}{l}\text { - Maquetación horizontal a } 3 \text { (superior, medio e inferior)/ 2/ Otra } \\
\text { - Maquetación vertical a } 1 \text { columna/ a } 2 \text { columnas/ a } 3 \text { columnas/ } \\
\text { Otra }\end{array}$ \\
\hline Contenidos portada & $\begin{array}{l}\text { - Principales titulares/ Principales titulares secciones/ Todos los } \\
\text { titulares } \\
\text { - Titular con sentido autónomo } \\
\text { - Entradilla/Lead: Si (Fragmentado/Completo)/No }\end{array}$ \\
\hline Usabilidad & $\begin{array}{l}\text { - Ampliar texto } \\
\text { - Ampliar foto } \\
\text { - Navegación intra (dentro de la sección) } \\
\text { - Navegación inter (entre secciones) } \\
- \text { Instrucciones de uso }\end{array}$ \\
\hline
\end{tabular}

DOI: ri14.v11i2.591 | ISSN: 1697-8293 | Año 2013 Volumen 11 N² 2 | ICONO14 


\begin{tabular}{|c|c|c|}
\hline Elemento & \multicolumn{2}{|l|}{ Indicadores } \\
\hline Personalización & \multicolumn{2}{|l|}{$\begin{array}{l}\text { - Menús } \\
\text { - Secciones } \\
\text { - Guardar noticia }\end{array}$} \\
\hline Geolocalización & \multicolumn{2}{|c|}{$\begin{array}{l}\text { - Lugar usuario } \\
\text { - Meteorología } \\
\text { - Etiquetado de contenidos }\end{array}$} \\
\hline Participación & \multicolumn{2}{|c|}{$\begin{array}{l}\text { - Alertas } \\
\text { - Comentar noticia } \\
\text { - Votar noticia } \\
\text { - Crear contenidos } \\
\text { - Compartir Facebook } \\
\text { - Compartir Twitter } \\
\text { - Compartir correo electrónico }\end{array}$} \\
\hline Multimedialidad & $\begin{array}{l}\text { - Galería de fotos } \\
\text { - Galería de videos } \\
\text { - Enlace a radio }\end{array}$ & $\begin{array}{l}\text { - Integrada } \\
\text { - General }\end{array}$ \\
\hline Modelo de negocio & \multicolumn{2}{|c|}{$\begin{array}{l}\text { - Free. Con/ sin publicidad. Formatos publicitarios localizados. } \\
\text { - Freemium } \\
\text { - Pago }\end{array}$} \\
\hline
\end{tabular}

Tabla $n^{\circ}$ 3: Modelo de análisis aplicado. Fuente: Elaboración propia

Otras observaciones relacionadas con cada uno de los aspectos del presente análisis fueron tenidas en cuenta, aunque dichas opciones no fueran sistematizadas y han contribuido al enriquecimiento de los resultados.

\section{Resultados obtenidos}

Para la presentación de los resultados del análisis, se ha decidido contemplar, en primer lugar, las aplicaciones de Android y, en segundo lugar, de i0s. En determinados aspectos, se ofrecerá una lectura de conjunto. Se seguirá en todo momento el mismo tipo y orden de los ítems de análisis previamente expuestos. Los resultados del análisis planteado muestran que: 


\subsection{En cuanto a Diseño}

La estructura de diseño más común en las aplicaciones analizadas es una estructura tripartita, consistente en: 1 . Cabecera del diario (la marca periodística de la aplicación con la tipografía y colores corporativos correspondientes); 2 . Subencabezado con el Menú de Secciones; 3. Cuerpo o parte más extensa donde se exponen en vertical los titulares de las noticias de Portada ${ }^{6}$.

Ésta, como decimos, es la estructura más común, que podemos encontrar en un $50 \%$ (7 de las 15) de las aplicaciones para Android analizadas. Existen fórmulas más sencillas (a 2, como en el caso de la app de Marca, siendo la parte superior para encabezado y secciones y la inferior para el cuerpo de titulares) o más complejas (el mayor número de niveles en el diseño de portada lo encontramos en el diario Mundo Deportivo, al desplegar el Menú, donde pueden identificarse hasta 5 niveles en el diseño de portada: Servicios, Secciones, Cabecera, Subsecciones y Cuerpo de titulares).

En cuanto a las aplicaciones para iOS, se estructuran también predominantemente (14 de las 18) en tres espacios, con dos fórmulas destacadas:

Cabecera, Cuerpo y Menú inferior con secciones (en 7 de 18).

Cabecera, Subencabezado con Menú de Secciones y Cuerpo de titulares de las noticias, es decir la misma fórmula que en las aplicaciones para Android, presente en 7 de las 18 apps analizadas.

En las apps para Android, en cuanto a la maquetación en vertical de Portada, predomina el diseño a una columna para la noticia principal y a dos columnas para el resto, donde la fotografía (en pequeño tamaño) se ubica a la derecha o izquierda del titular. Esto ocurre en 7 de las 15 apps analizadas.

En las apps para iOS, la maquetación vertical de Portada es a dos columnas en 7 de las 18 aplicaciones, siendo una columna más amplia para el texto y otra más estrecha para la imagen. Esto ocurre también, si la noticia presenta foto, en otros cuatro modelos de aplicaciones.

Las apps de La Vanguardia, Mundo Deportivo y de $A B C$ para ambos sistemas son las únicas que maquetan a una columna. De esta forma, la fotografía presenta un tamaño más grande y puede dedicarse más espacio al texto de titular/entradilla/ subtítulos si se desea. Condensa menos información, pero se presenta más claramente, favoreciendo su visualización.

DOI: ri14.v11i2.591 | ISSN: 1697-8293 | Año 2013 Volumen 11 N² | ICONO14 


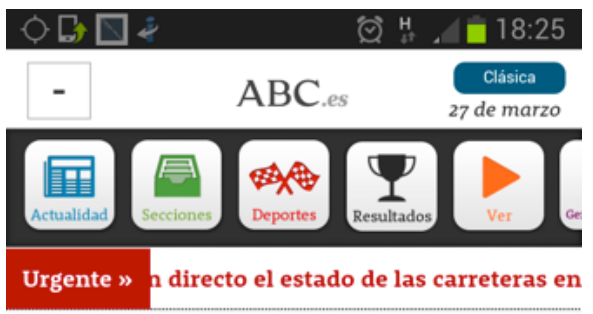

ESPAÑA 》

El juez Ruz investigará los «papeles de Bárcenas»

27/03/2013 25:49

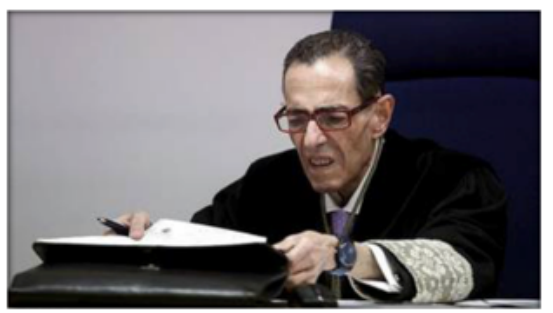

La Audiencia Nacional resuelve que Gómez Bermúdez, que intentó hacerse con el caso, no es el magistrado competente

ESPAÑA \#

Rajoy y Mas mantuvieron esta semana una reunión de carácter reservado en Madrid 27/0a/2013 17:12

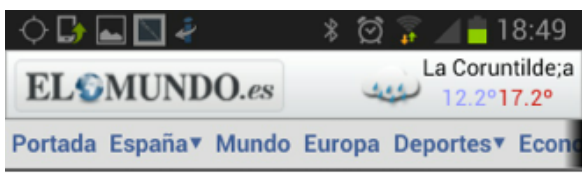

Guindos revela que fue el Banco de España quien aconsejó la nacionalización de Bankia

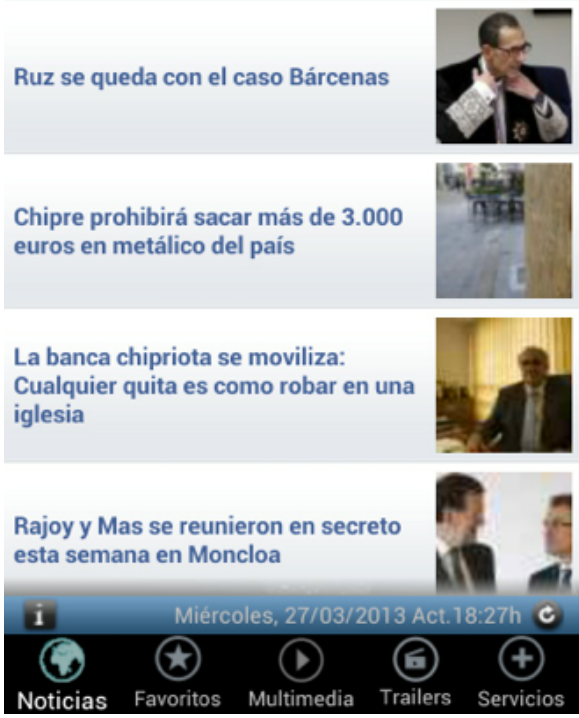

Imágenes 1 y 2: Maquetación a 1 y a 2 columnas en ABC y El Mundo (ambas para Android) respectivamente.

\subsection{Contenidos de Portada}

No presentan lead o entradilla las noticias de portada en 7 de las 15 aplicaciones Android estudiadas, ni 12 de las 18 para iPhone, que recurren a la presentación de titulares y obvian el primer párrafo de la noticia. Se han localizado además, seis aplicaciones en total (sobre 33) que presentan un lead fragmentado, es decir, una entradilla con un texto fragmentado, que requiere pulsar en la noticia para leerla al completo.

Y tres aplicaciones en las que aparecen "rotos" los titulares (El Heraldo de Aragón para Android e iOs y El Correo Español para iPhone).

Ello podría tener una doble explicación: bien, se pretende un modo de incentivar la atención del lector, bien no se está aplicando un modelo de estructura de la información adaptado a la pantalla del smartphone. 
Realizada la comprobación, se demuestra que el texto de la entradilla de la app reproduce exactamente la escrita para la web, pero en un caso se corta y en otro se mantiene completa. Vemos el ejemplo en la web y la app de iPhone en la misma noticia de El Heraldo de Aragón:
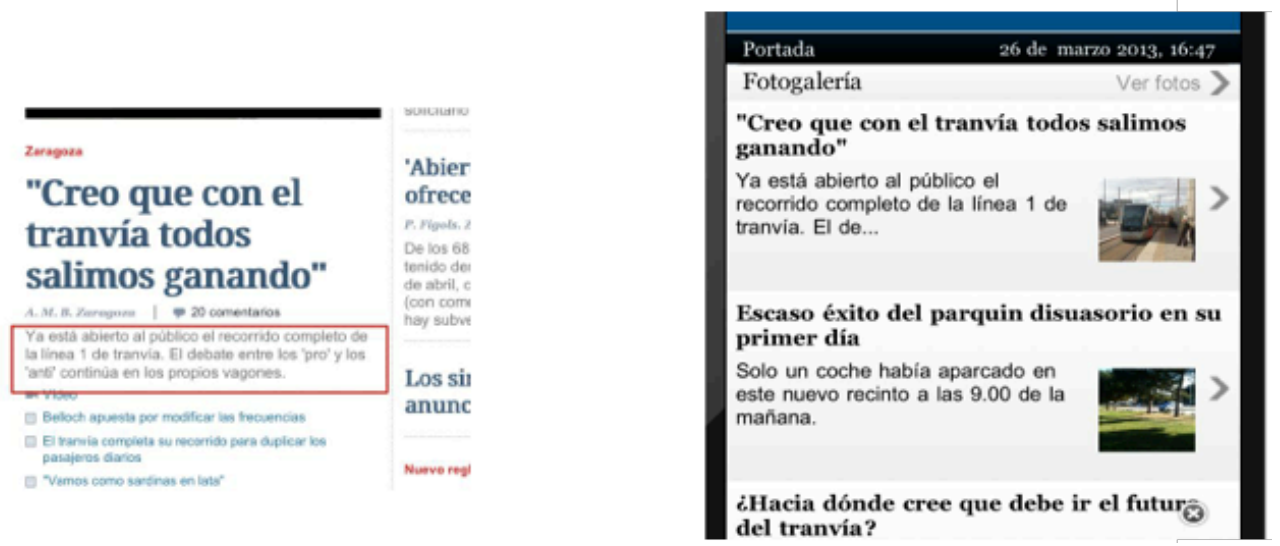

Imágenes 3 y 4: Capturas de pantalla de la web y la app para iOS de El Heraldo de Aragón.

\subsection{Usabilidad}

La opción de ampliación de texto es mayoritaria, siendo factible en 11 de las 15 aplicaciones para Android (bien en el menú de Ajustes, o en el icono textual Aa), no así la ampliación de la fotografía, sólo disponible en dos de ellas. Con respecto a las apps para iOS, se puede ampliar texto en 16 de los 18 medios. La opción de ampliación de imagen solo en una.

La posibilidad de navegación de noticia a noticia dentro de la misma sección es posible en once de las quince apps para Android, en siete de las dieciocho para iPhone.

Sin embargo, para cambiar de sección lo habitual es tener que pasar necesariamente por la portada de Sección o ir al botón desplegable de secciones. Esto ocurre en todas las aplicaciones estudiadas, a excepción del diario Marca para iOS. Las instrucciones de navegación e incluso de los botones de la app están presentes en sólo una de las aplicaciones analizadas, la del diario Mundo Deportivo. 


\section{Recursos de Usabilidad}

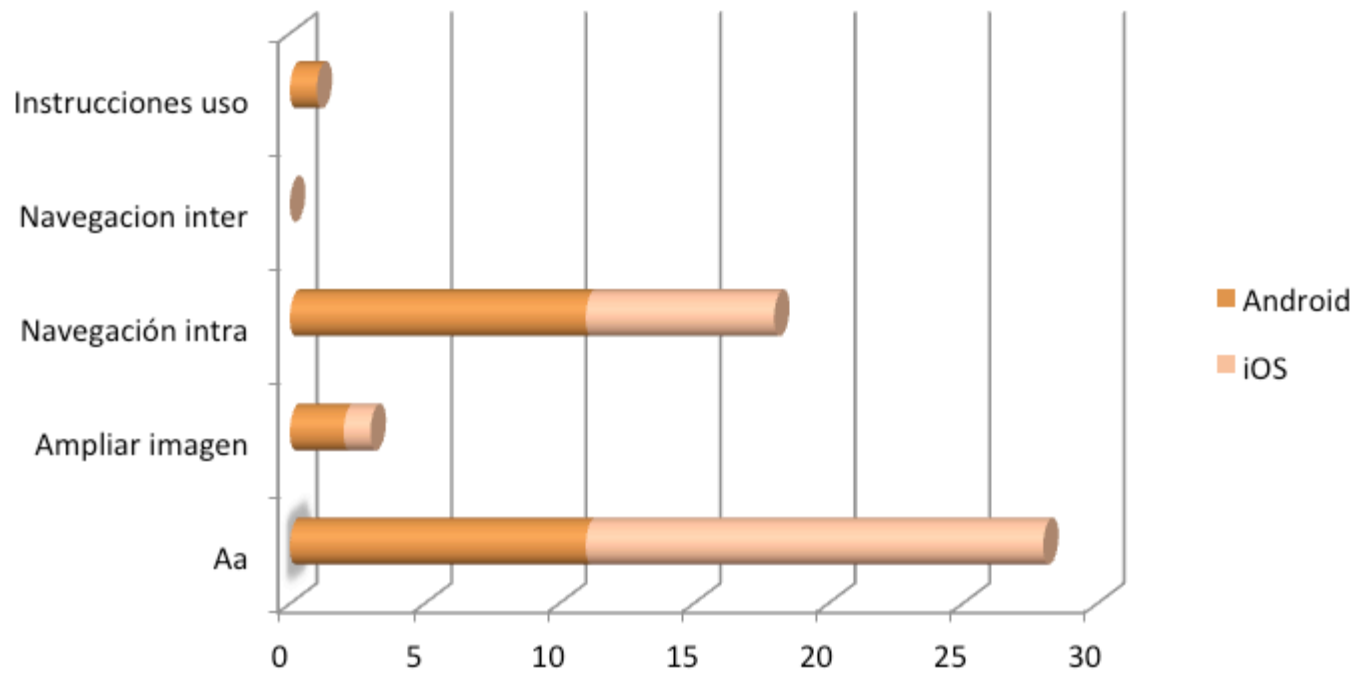

Gráfico 1: Opciones de usabilidad en las apps para Android/iOS. Fuente: Elaboración propia.

\subsection{Personalización}

Es uno de los apartados del análisis cuyos resultados son más pobres. En un solo caso - la app del deportivo Marca para Android- el usuario puede personalizar el color de la fuente o del fondo de la pantalla (sólo el fondo en la app para iOS).

En la app de El Pais puede personalizarse el orden de las secciones dentro del Menú, tanto en su app para Android como para iOS.

Una opción predominante es la creación de una sección con las noticias guardadas por el usuario. En 19 de las 33 apps, pueden guardarse las noticias elegidas que pasan a integrarse en la sección Favoritos o Archivo.

Puede hablarse de personalización en las secciones de los diarios Marca y As, que permiten personalizar las noticias $\mathrm{y}$, en el segundo caso, también las alertas, en función del equipo de fútbol del que sea seguidor el usuario.

Puede personalizarse la Portada en sólo tres aplicaciones y otra sección (Deportes o Local) en tan sólo dos apps sobre el total analizado. 


\subsection{Geolocalización}

Constituye la gran ausente de los resultados de este análisis. No se tienen en cuenta opciones de geolocalización de la información en función del lugar donde se encuentra el usuario en apenas ningún caso.

Las únicas excepciones pueden encontrarse en la aplicación de El Mundo que permite configurar la localización en el servicio de meteorología y en las apps de La Verdad y de Diario Vasco para el mismo servicio y para el de cartelera de cine.

Pueden geolocalizarse servicios (hoteles, restaurantes, locales u oferta de ocio) en las apps para iOS de La Verdad, Diario Vasco, Faro de Vigo, La Nueva España e Informacion.

\subsection{Posibilidades de participación del usuario-lector}

La opción más habitual es la de reenviar contenido publicado por e-mail, presente en 32 de las 33 aplicaciones analizadas (sólo ausente en la app de Levante para Android).

En redes sociales, cabe hacer una diferenciación según el sistema para el que la aplicación haya sido creada:

- En las apps de Android, Google+ como herramienta para interactuar (en ocho de las quince) iguala a Facebook y a Twitter (presentes también en ocho de las apps del estudio). El resto de las opciones son minoritarias. La posibilidad de comentar noticias podemos encontrarla en cinco de las quince aplicaciones. La opción de mandar foto/video en sólo cuatro (La Vanguardia, Mundo Deportivo, La Verdad y Diario Vasco). Las alertas informativas están presentes en las apps de los diarios deportivos As y Sport y la opción de votar noticias en solo dos del conjunto de aplicaciones analizadas. Al margen de las posibilidades de participación contempladas, ocho de las catorce apps-aquellas donde se potencia Gmail y Google+también permiten compartir contenido en Skype, Whats App, Chat On, Bluetooth o Flipboard.

- En las apps para iPhone, predomina el uso de Facebook y de Twitter en cuanto a las redes sociales. Ambas herramientas se encuentran en el $100 \%$ de los casos analizados. Google + sólo está presente en dos apps. La posibilidad de comentar noticias está presente en ocho de las 18 apps, mientras que la opción de

DOI: ri14.v11i2.591 | ISSN: 1697-8293 | Año 2013 Volumen 11 N² | ICONO14 
votación en apenas una. La opción de mandar foto/vídeo sólo la encontramos en la app de Mundo Deportivo. La opción de activar alertas informativas se halla, al igual que en Android, en los diarios deportivos As y Sport.

\subsection{Recursos multimedia}

Los recursos multimedia que incluyen las aplicaciones se mantienen como sección independiente de forma predominante. En esta línea, tienen sección de Videos 18 de las 33 aplicaciones, mientras que la sección de Fotos está presente en una proporción algo superior (19 sobre 33).

Por el contrario, sólo diez de las apps de estudio integran videos en las noticias y ninguna de ellas integra galería de fotos en noticias.

\section{Presencia de recursos multimedia}

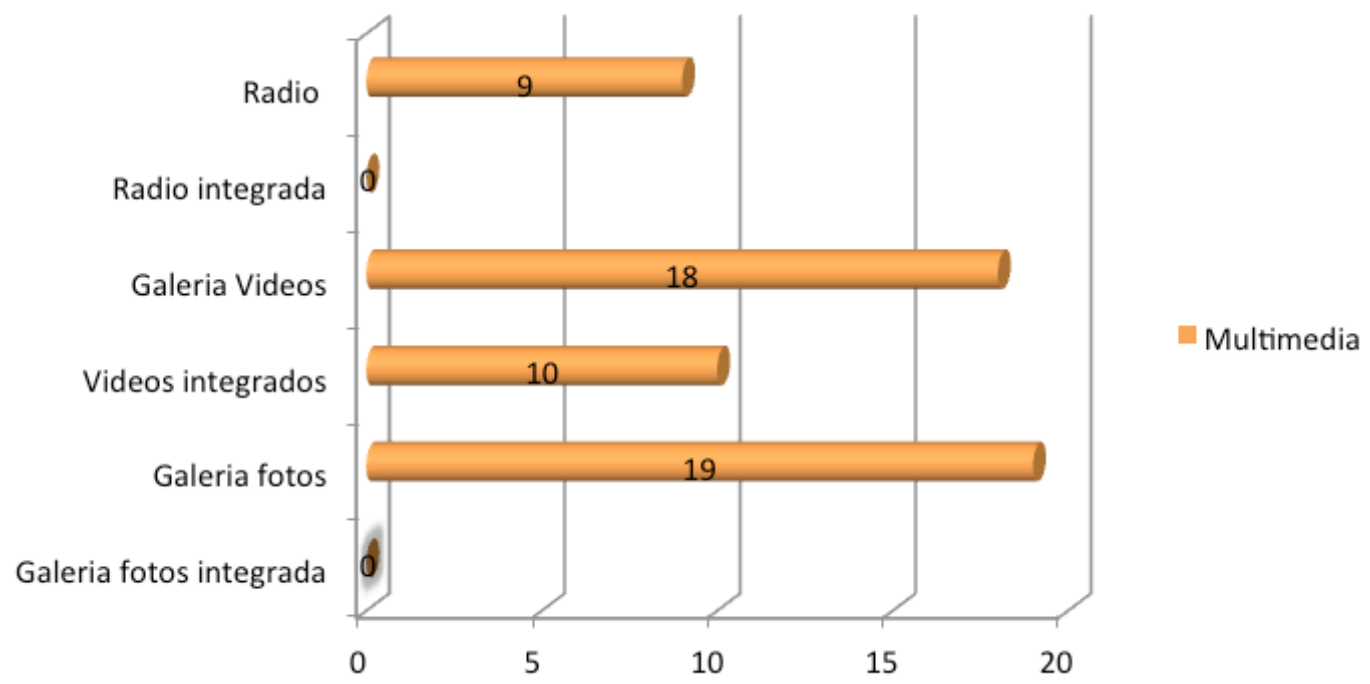

Gráfico 2: Presencia de recursos multimedia en las apps para Android/ iOS.

Fuente: Elaboración propia.

En cuanto a la radio, ninguna de las apps presenta cortes de audio en las noticias, sí existe la opción de escuchar radio en cinco de las catorce aplicaciones (para ambos sistemas) en concreto: ABC Radio, Radio Mundo Deportivo, Radio Marca (en la app de Marca y de El Mundo) y RAC 1 y RAC 5 (en la app de La Vanguardia).

La única de las apps que presenta un lector de noticias es El Mundo, que pre- 
senta como servicio un lector automático de noticias (llamado Rosa) tanto para titulares de última hora, como para noticias más vistas y también para el tiempo.

\subsection{Modelo/s de negocio}

La publicidad sigue siendo el canal de ingresos prioritario en cuanto al modelo de negocio presente. En la aplicación de El Heraldo se incluye en la sección Publicidad el número de contacto para quienes estén interesados en incluir publicidad en la aplicación.

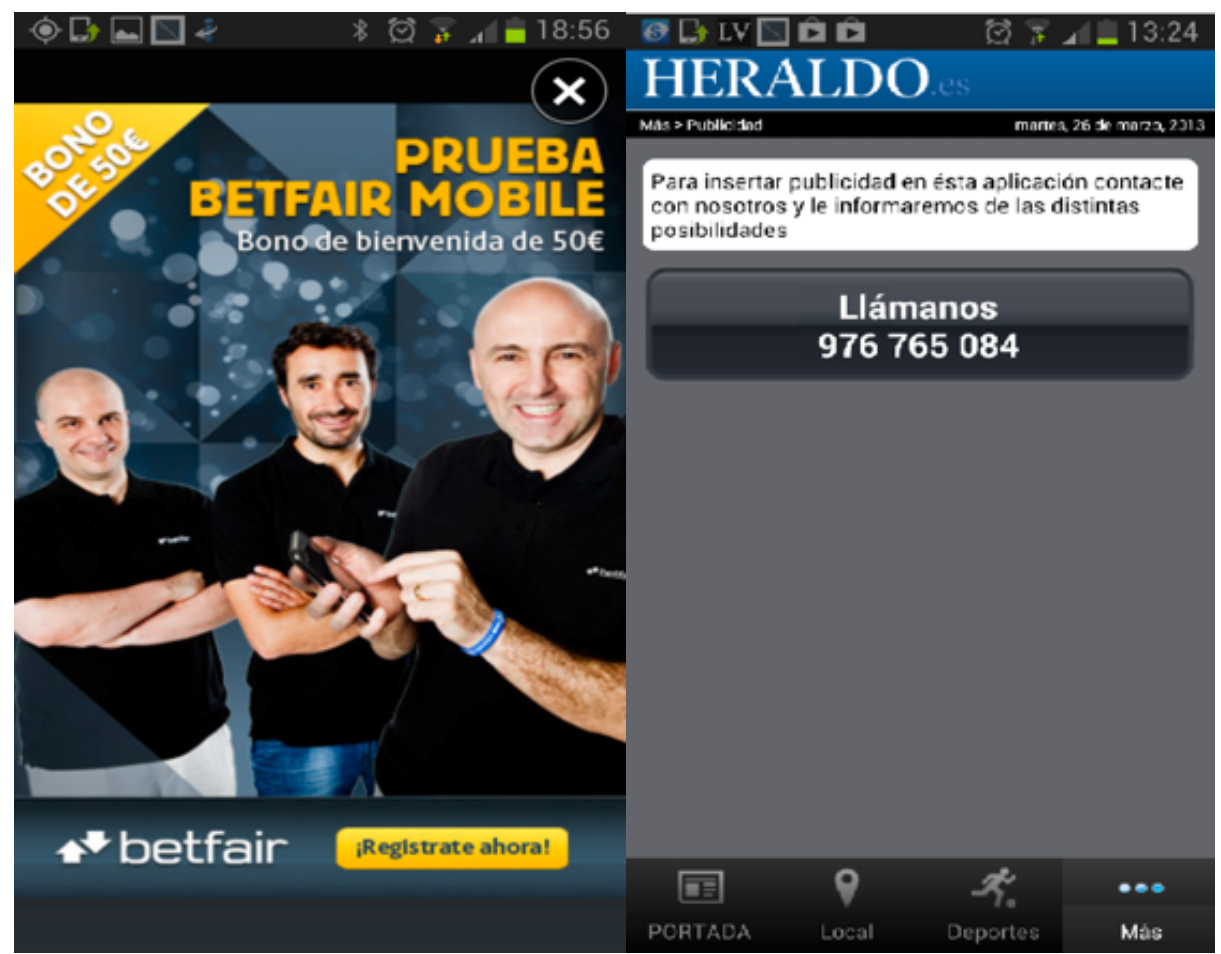

Imágenes 5 y 6: PLlamada a inserciones publicitarias de Heraldo y pop-up window del diario As.

Los contenidos son gratuitos, pero a cambio, el usuario-lector convive con los formatos publicitarios, bien en forma de banner o de pop-up window como formatos predominantes.

Otros modelos de negocio podemos encontrarlos en: 
- La app de La Vanguardia, que ofrece la opción de hacerse suscriptor y adquirir contenidos del diario previo pago.

- Las aplicaciones de $A B C$, La Verdad o Diario Vasco, que derivan a Kiosko y más para el acceso también a través del Smartphone de contenidos extra.

- La aplicación de El Periódico de Catalunya para iPhone, que requiere del registro y de la suscripción del usuario para entrar a la app.

\section{Discusión de los resultados}

Del análisis efectuado, se concluye que es en los aspectos de personalización, geolocalización, multimedia y participación donde se hallan las principales carencias de las aplicaciones desarrolladas. Es en esos cuatro ámbitos donde puede construirse un nuevo modelo informativo para los móviles inteligentes.

Las posibilidades de personalización debieran haberse convertido en uno de los puntos fuertes de las aplicaciones. Siendo el smartphone un dispositivo de uso personal, adaptable en cuanto a tonos de llamada y de sms, fondo de pantalla, fundas, etc., lo lógico sería que las aplicaciones permitiesen su acomodo a los gustos y preferencias informativas y de uso del lector.

Sin embargo, en cuanto a contenido, sólo puede personalizarse el contenido de la portada y de alguna sección de escasas aplicaciones (dentro de unas opciones muy limitadas), $\mathrm{y}$, en cuanto a formato, el color de fondo y de fuente tipográfica en uno de los casos analizados. Este es, sin duda, uno de los caminos abiertos para las nuevas versiones de aplicaciones, en el que la industria debiera comenzar a avanzar.

Las opciones de geolocalización, por su parte, están siendo ignoradas al servicio de la información. Si en los diarios nacionales puede resultarnos su empleo más forzado, en los diarios locales -entendiendo como tal aquellos que presentan un sistema de ediciones enfocado a un ámbito geográfico determinado- su infraempleo carece de sentido estratégico. Aplicándolo a un ejemplo de los analizados, el diario de la Corporación Voz de Galicia, La Voz de Galicia, cabecera cuyo ámbito de difusión prioritario es la Comunidad Gallega, consta de un sistema de trece ediciones locales ${ }^{7}$. Sin embargo, ni la app creada para Android ni la desarrollada para el sistema de Apple, incluyen en sus secciones la información local, ni tampoco se emplean las opciones de geolocalización del usuario para conocer las noticias de

ICONO14 | Año 2013 Volumen 11 N² | ISSN: 1697-8293 | DOI: ri14.v11i2.591 
su zona. Y lo mismo para otros diarios autonómicos/locales analizados, tales como Diario Vasco, Levante, La Verdad, etc. que podrían ofrecer al usuario la opción de conocer las noticias más próximas en función de su localización, una vez solicitado el permiso correspondiente al usuario-lector.

Llama la atención que las aplicaciones del grupo Prensa Ibérica para iOS permitan geolocalizar servicios (hoteles, restaurantes, agenda, pubs, etc.), pero no información de actualidad.

En el ámbito multimedia, a pesar de que se están incorporando las galerías de imágenes y de videos como recursos/ secciones de contenido dentro del Menú de Secciones (mayoritariamente, pero aún así en un 56\% de las apps analizadas), queda mucho que hacer en cuanto a la integración y enriquecimiento de las noticias. Los videos integrados en la información -opción minoritaria, según se desprende del análisis- fomentan una información con mayor carga visual, una posibilidad importante para un dispositivo que se emplea en momentos de ocio intersticial (momentos de espera, de transporte o desplazamiento entre distintas actividades...) y cuyas características técnicas (tamaño de pantalla fundamentalmente) tampoco favorecen una lectura continua y en profundidad. El audio, o cobertura sonora de la información, serviría también para potenciar su capacidad informativa y cubrir dicha particularidad. Sin embargo, la radio se plantea como recurso independiente de las noticias, bajo la intencionalidad de escuchar la radio mientras se navega por la aplicación, por tanto, aportando lo mismo que la conexión a la radio desde el móvil (una posibilidad para la que no se necesita conexión a la Red).

Resulta llamativo que grupos de comunicación multimedia como puede ser el grupo Prisa, no emplee los recursos procedentes de otros de sus medios (p. ej. la Cadena Ser) para enriquecer las noticias de la aplicación de El País con cortes de audio que permitan ampliar la noticia o escuchar las voces de sus protagonistas. Lo mismo para la Corporación Voz de Galicia, que dispone de Radio Voz además del canal de TDT $V$ Televisión y, por tanto, de recursos multimedia con los que enriquecer las noticias de su aplicación.

Prensa Ibérica, por su parte, también ha diversificado su actividad hacia el audiovisual. En este sentido, el hecho de que posean el canal Levante tv se contradice con que las aplicaciones del diario Levante para Android y para i0s carezcan de galería de videos o de videos integrados en las informaciones.

En lo relativo a la participación del usuario-lector, a nivel de redes sociales,

DOI: ri14.v11i2.591 | ISSN: 1697-8293 | Año 2013 Volumen 11 N² | ICONO14 
comparecen las diferentes estrategias de los dos gigantes tecnológicos: Google y Apple. Mientras las aplicaciones para el iPhone priorizan Facebook y Twitter como redes sociales, las apps desarrolladas para Android dan mayor protagonismo a la red social de Google. Los intereses y contraintereses empresariales explican ambas tendencias. En cualquier caso, lo llamativo reside en la poca "participación real" otorgada al usuario. La opción de comentar noticias, ya de cierta tradición en web, es minoritaria en el conjunto de apps. Y yendo un paso más allá, ¿dónde se encuentra el protagonismo del prosumer? Las aplicaciones del grupo Godó son las únicas que escapan a la norma, en menor medida las aplicaciones de Vocento para Android, permitiendo al usuario mandar sus videos/ texto o imágenes al diario.

Las potencialidades del smartphone para tomar fotos o videos que puedan dar la visión de los usuarios-lectores sobre un determinado tema representan otra de las vías necesarias a la hora de desarrollar una nueva generación de aplicaciones para smartphone.

La evolución, por lo tanto, pasa por aplicaciones más personalizables, con información adaptable al usuario, que tendrá a su disposición recursos audiovisuales integrados en la noticia para informarse, además de aprovechar las posibilidades multimedia de su smartphone, si así lo desea.

En cuanto a los modelos de negocio imperantes, la publicidad continúa siendo la principal apuesta de los grupos empresariales multimedia, aún en contexto de caída de los ingresos publicitarios debido a la actual situación económica ${ }^{8}$.

El modelo de exclusiva gratuidad de los contenidos para una plataforma que está empezando a explotarse proporciona mayor seguridad y menor riesgo de fracaso. Como soporte que contribuya a fidelizar la marca funciona a raíz de un conocimiento previo del medio, del que ya se es lector habitual (por eso se descarga la aplicación y por eso se mantiene en pantalla).

“Em termos comerciais, depois da cultura da gratuidade que, em termos jornalísticos, foi fomentada pelos próprios conglomerados e que se tornou um desafio para as empresas do setor, o jornalismo móvel parece trazer un novo alento", explican Rublescki et al. (2013: 136).

Es probable que el modelo de negocio para las apps, no obstante, se supedite al modelo de negocio online, que lleva más tiempo intentando definirse. Según Casero-Ripollés (2010: 601), “en la actual coyuntura, donde predomina el ensayoerror, parece que las fórmulas mixtas, como el freemium, que combinan cobro y

ICONO14 | Año 2013 Volumen 11 N² | ISSN: 1697-8293 | DOI: ri14.v11i2.591 
gratuidad, se alzan como la mejor solución". En la siguiente generación de aplicaciones, quizás corresponda verlo.

\section{Conclusiones. Nuevas necesidades para un nue- vo "medio"}

Tras una evolución que ha durado apenas una década, nos hallamos en la era de las aplicaciones. En su mayoría, las empresas periodísticas españolas-al menos, las editoras de las cabeceras más leídas en nuestro país- conciben el smartphone como un nuevo soporte para el que crear contenidos informativos y para el que ya han desarrollado una aplicación de noticias.

Especialmente para el dispositivo de Apple, el iPhone, el primero en llegar al mercado, lo que ha conllevado que forme parte de las estrategias de periodismo móvil de todas las cabeceras analizadas (algo, que como hemos visto, todavía no ocurre para los dispositivos que emplean Android).

Pero la evolución no ha llegado a su grado de madurez máximo. El "nuevo medio" (Scolari et al., 2009) requiere que se tengan en cuenta sus características propias para optimizar las posibilidades de su empleo como herramienta informativa.

Las empresas periodísticas españolas necesitan desarrollar modelos informativos para smartphone amoldables a las preferencias de los usuarios, que permitan explorar su naturaleza móvil, enriquecidas en lo audiovisual y más participativas, acordes con la tendencia de consumo social de la información que ha permitido el desarrollo de las redes sociales.

Coincidiendo con lo afirmado en el estudio de Canavilhas y Cavallari (2011: 65) “a pesar desta melhoria geral, registrada entre 2009 e 2011, as plataformas móveis atuais possuem características técnicas ainda pouco exploradas, que permitem oferecer tipos realmente novos de produtos informativos".

Esos nuevos productos informativos han de ser pensados, diseñados y dotados de contenido atendiendo a las características singulares del nuevo medio, así como a sus dinámicas de uso.

La generación de esa exclusividad para smartphone en cuanto a diseño y contenido ayudará a promover un modelo de negocio también diferenciado, que pueda incentivar una menor dependencia de la publicidad y la predisposición a la suscripción o al pago puntual por contenidos vinculados al servicio informativo por

DOI: ri14.v11i2.591 | ISSN: 1697-8293 | Año 2013 Volumen 11 N² 2 | ICONO14 
parte del usuario.

La comparativa y la replicación del presente estudio en un futuro inmediato permitirá conocer la evolución del modelo periodístico de los diarios españoles para smartphone. La madurez y las nuevas versiones de aplicaciones ayudarán a consolidar el potencial informativo de la plataforma.

\section{Notas}

[1] Disponible en: http://es.slideshare.net/IAB_Spain/iv-estudio-anual-en-mobile-marketing.

[2] El diario La Verdad (Vocento S.A.) cuenta con tres ediciones (Murcia, Alicante y Albacete) y sus respectivas tres aplicaciones informativas, pero a los efectos del presente trabajo se ha tenido en cuenta la aplicación de La Verdad de Murcia pues las tres apps presentan el mismo diseño y esquema de contenidos.

[3] Resultó excluida del análisis la aplicación del diario gallego Faro de Vigo puesto que, a pesar de haber sido descargada en varias ocasiones, siempre generó error, no siendo posible la navegación y exploración de dicha app.

[4] Se excluyó del análisis de aplicaciones para iOS la app de El Periódico de Catalunya por exigir la condición de suscriptor/a para el acceso a los contenidos de la aplicación. Tuvo que ser excluida la app de La Razón porque no permite la descarga de los contenidos informativos del diario.

[5] Para los tres recursos multimedia (fotos, videos y audio), se diferenció si funcionaban de modo independiente y al mismo nivel que el resto de secciones (Economía, Deportes, etc.) o si estaban integradas en la noticia (galería de fotos de la noticia, p.e.).

[6] En la app de ElPais, la estructura tripartita altera el orden, de modo que aparece el menú de secciones arriba, en segundo lugar la cabecera del diario y en último término el cuerpo de titulares de las noticias.

[7] Consultar http://www.lavozdegalicia.es para conocer el sistema de delegaciones.

[8] En prensa, la inversión publicitaria ha caído un 12\% de 2009 a 2011, pasando de 1.117,9 millones de euros a 9939,9 en 2011 (AEDE, 2012).

\section{Referencias}

Aguado, J. M. y Martínez, I. J. (2008): “La comunicación móvil en el ecosistema

ICONO14 | Año 2013 Volumen $11 \mathrm{~N}^{\circ} 2$ | ISSN: $1697-8293$ | DOI: ri14.v1 1i2.591 
informativo: de las alertas SMS al Mobile 2.0", en Trípodos, 23, pps. 107-118. AIMC (2013): $15^{a}$ Encuesta a Usuarios de Internet, Navegantes en la Red.

Disponible en: http://www.aimc.es/-Navegantes-en-la-Red-.html [20/03/2013].

Asociación de Editores de Diarios Españoles (AEDE) (2012): Libro blanco de la prensa diaria en España. Año 2013. Madrid: Asociación de Editores de Diarios Españoles.

Canavilhas, J. (2009). “Contenidos informativos para móviles: estudio de aplicaciones para iPhone". Revista Textual \& Visual Media, 2, pps.61-80. http://hdl.handle.net/10400.6/684

Digital News Test Kitchen (2010). "In-depth news for smartphones". University of Colorado, Boulder School of Journalism \& Mass Communication. Disponible en http://testkitchen.colorado.edu/projects/reports/smartphone/ [15/03/2013].

García Hervás, J. M. (2010):“Redes sociales en el móvil”, en Telos: Cuadernos de comunicación e innovación, $\mathrm{n}^{0}$ 83, pps. 8-12. Disponible en: http:// sociedadinformacion.fundacion.telefonica.com/seccion=1268\&idioma=es_ ES\&id=2010051711250001\&activo=6.do [01/09/2012].

Lerma Noriega, C. y Cobos Cobos, T. (2013). “Desarrollo del Periodismo en Línea y Móvil en los diarios mexicanos", en González Molina, Canavilhas, Carvajal, Lerma y Cobos (coord..) (2013): Hacia el periodismo móvil, Colección Mundo Digital (3), Revista Mediterránea de Comunicación, pps. 50-71. Disponible en: http://comiber.recinet.org/rmedcom/3Periodismo\%20Movil.pdf [01/05/2013]

Navarro Güere, H. y Lisboa Neves, A. (2012). mPeriodismo. Introducción a las Apps de noticias para dispositivos móviles, en Congreso Internacional AEIC "Comunicación y Desarrollo en la Era Digital". Tarragona, 18-20 enero de 2012. Disponible en: http://www.aeic2012tarragona.org/comunicacions_cd/ ok/104.pdf [09/12/12]

Purcel, K., Rainie, L., Rosenstiel T. y Mitchell, A. (2011). Spring 2011 iPad survey results. Reynolds Journalism Institute -DPA. Disponible en http://rjionline. org/news/rji-dpa-spring-2011-ipad-survey-results [09/04/2013].

Rublescki, A., Barichello, E. y Dutra, F. (2013): “Jornalismo em dispositivos móveis: os jornais brasileiros", en Canavilhas, J. (coord.): Notícias e 
mobilidade. Jornalismo na era dos dispositivos móveis, Covilhã, LabCom. Disponible en: http://www.livroslabcom.ubi.pt/book/94 [10/05/2013] Sánchez Valverde, E. y Aguado, J. M. (2010). “Dispositivos móviles y convergencia digital en los grupos de comunicación españoles: la perspectiva de los profesionales". En II Congreso Internacional AE-IC “Comunicación y Desarrollo en la Era Digital". Málaga, 3-5 febrero de 2010. Disponible en: http://www. aeic2010malaga.org/upload/ok/95.pdf [03/03/13]

Scolari, C., Navarro Güere, H., Pardo Kuklinski, H., García, I. y Soriano, J. (2009): "Comunicación móvil: actores y producción de contenidos en Cataluña", en Comunicación y Sociedad, vol. 22, n² 2, pps. 159-185.

UIT (2010): Information Society Statistical Profiles 2009: Europe. Disponible en http://www.itu.int/dms_pub/itu-d/opb/ind/D-IND-RPM.EUR-2009-R1-PDF-E. pdf $[20 / 12 / 2011]$

ICONO14 | Año 2013 Volumen $11 \mathrm{~N}^{\circ} 2$ | ISSN: 1697-8293 | DOI: ri14.v11i2.591 